\title{
Oxidation and Bio-decontamination Effects of Impulsive Discharges in Atmospheric Air
}

\author{
S. Li, I. V. Timoshkin, Senior Member, IEEE, M. Maclean, S. J. MacGregor, Senior Member, IEEE, \\ M.P. Wilson, Member, IEEE, M. J. Given, Senior Member, IEEE, T. Wang, J. G. Anderson
}

Abstract-Chemical oxidation and the bactericida 8 capabilities of non-thermal plasma discharges can be used if 9 different practical applications such as bio-decontamination 50 sterilisation of medical equipment, waste water treatment, syn-gas 1 treatment and others. In this paper, the oxidation and bio decontamination effects of impulsive plasma discharges which propagate across a liquid sample/air interface (surface discharges), 3 and through the bulk of a liquid sample (direct discharges), have 4 been investigated. The oxidising capability was analysed b $\overline{\$} 5$ measuring the degree of decolourisation of indigo carmine dye in 6 water solutions. Gram-negative and Gram-positive bacteriaz7 E. coli and S.aureus, respectively, were used as model microorganisms in the investigation of the biocidal effects of plasma discharges. Surface and direct plasma discharges were 59 generated by high-voltage impulses of both polarities, wit5 0 magnitudes of $20 \mathrm{kV}, 24 \mathrm{kV}$ and $28 \mathrm{kV}$, the chemical oxidation an 61 bio-decontamination capabilities of such discharges have beeß2 obtained and analysed. It has been established that the defining 3 factor in the chemical and biological effects of plasma discharges is the normalised delivered charge (dose). The results obtained in this study show that surface discharges have greater bio 65 decontamination capability as compared with direct transiene6 plasma discharges. Also, it was shown that the decontaminatio67 rate of E.coli is more than double than that of $S$. aureus.

Index Terms - Non-thermal plasma discharges, OH-radicals 69 Bio-decontamination, Oxidation.

\section{INTRODUCTION}

$\mathrm{N}$ on-thermal plasma discharges have attracted th 73 attention of researchers and engineers who are working on the development of novel methods for oxidation an $\$ 6$ bio-decontamination. It has been shown that atmospheric 77 pressure plasma discharges produce significant oxidation an $\$ 8$ bactericidal effects [1]. As a result, multiple practicał 9 applications are now being developed, including non-therma 8 plasma discharges for gas treatment, water purification, biog1 decontamination and wound treatment [2-3]. However, th 82 exact mechanisms of the chemical and microbiological effect8 33 of transient atmospheric plasma (TAP) discharges are still nog fully understood. There are several factors which make 85 significant contribution to these processes: production of 6 chemically-active oxygen and nitrogen species, emission of U 87 light and generation of a strong electric field. TAP discharge 88 produce multiple chemically-active species including $\mathrm{OH}_{9}$ radicals, ozone, hydrogen peroxide, singlet oxygen, nitric dioxide, peroxynitrites and others [4-7]. $\mathrm{OH}$ radicals have the highest redox potential of $2.7 \mathrm{~V}$, amongst all oxygen-based reactive species [8], while the redox potential of superoxide anions is $2.42 \mathrm{~V}$, ozone is $2.07 \mathrm{~V}$ and hydrogen peroxide is 1.78 $\mathrm{V}$ [9]. In [10] and [11], it was shown that $\mathrm{OH}$ radicals have higher reaction rates than other species, including ozone: $\mathrm{OH}$ radicals are able to react with organic compounds significantly $\left(10^{6}-10^{12}\right.$ times) faster than ozone. Therefore, chemical species with high oxidizing capability play an important role in the chemical and microbiological activity of plasma discharges [12-14]. For example, it was suggested in [15] that $\mathrm{OH}$ radicals together with ozone produced by an underwater air plasma jet play a major role in the decomposition of methylene blue dye in water solution. Possible mechanisms of $\mathrm{OH}$ production at the plasma-water interface are discussed in [9], [16]; amongst these mechanisms are the disassociation of water molecules by energetic electrons and dissociative attachment of electrons to water molecules. Plasma discharges in water can produce other reactive oxygen species (ROS) with high redox potential such as superoxide anions, ozone and hydrogen peroxide [16], [17].

Different types of TAP discharges can result in different rates of production of these chemically-active species and, thus, can result in a different degree of chemical or microbiological activity. For further development of practical applications of TAP discharges, it is important to establish the optimal discharge topologies and, therefore, it is necessary to investigate the oxidation and microbiological efficacy of different types of discharges and their dependency on different discharge parameters, such as the magnitude and polarity of the applied voltage, the charge delivered during the plasma treatment and the discharge propagation path.

In this paper, the chemical and biological effects of pulsed discharges in atmospheric air which propagate across the interface between the sample under test (water-based dye solution and water-based agar seeded with microorganisms) and air, or through the bulk of the sample under test, have been studied. This approach allowed comparison of the biodecontamination and oxidation efficacy of surface and direct plasma discharges. The oxidation capability of TAP discharges was investigated using a water-based solution of blue dye (indigo carmine), the degree of decolourisation of this dye was obtained for different voltages, specific charges, and for different discharge propagation paths. Also, the bio- 
1 inactivation capability of the TAP discharges was investigate 46 2 using the Gram-negative and Gram-positive microorganismst7 3 E. coli and $S$. aureus, respectively. The results obtained in thi 8 4 study confirm that TAP discharges produce significant 9 5 oxidation and bio-decontamination effects, which will aid if 0 6 further development and optimisation of atmospheric plasm 51 7 treatment systems for practical applications, including the us $\mathrm{5}^{2}$ 8 of such plasma discharges in environmental and medica ${ }^{3}$ 9 technologies.

\section{EXPERIMENTAL SYSTEM}

The main aim of this study was to investigate the productios 8 of $\mathrm{OH}$ radicals in water-based solutions, and the chemicaj9 oxidation and microbiological decontamination capabilities of 0 two types of TAP discharges: surface discharges whicb1 propagate along the sample/air interface, and direct discharge 2 which propagate through the bulk of the sample. To conduc 83 this study, a dedicated experimental system was designed an 84 developed. This system includes a pulsed-power supply t 85 generate transient plasma discharges, different test cells to hol\&6 water solutions and microbiological samples, diagnostig7 devices to monitor high-voltage and current waveforms, an ai68 pump with a gas distribution board, and an ozone analyzer.

A diagram of this experimental system is shown in Figure 1. A TG-01 trigger generator (Samtech Ltd, Scotland) was used as a pulsed-power source, and the output of the pulse generator was connected to the high-voltage (HV) needle electrode located inside the test cell. The trigger generator was capable of producing positive and negative $\mathrm{HV}$ impulses with a peak magnitude of $30 \mathrm{kV}$ and a rise-time of $\sim 60 \mu \mathrm{s}[18]$. The pulse repetition rate used in the present study was 20 pulses per second (pps).

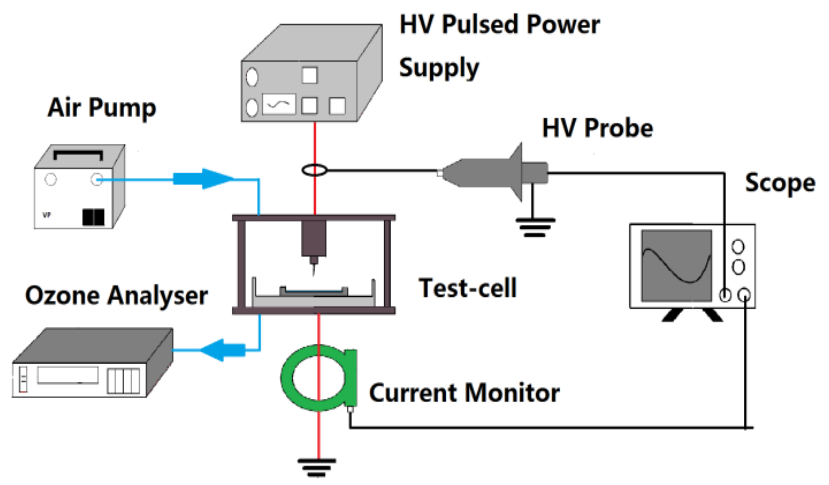

Fig. 1. Diagram of the experimental system used for decolorisation and microg7 biological inactivation.

The transient voltage waveforms associated with the discharges generated were monitored by a Tektronix P6015 HV probe (1000:1 division ratio, $75 \mathrm{MHz}$ bandwidth). The discharge current was monitored by a Pearson 6585 current 3 monitor (250 MHz bandwidth). The HV probe and the current ${ }_{4}^{3}$ monitor were connected to the high-impedance inputs of 94 Tektronix TDS 2024 digitizing oscilloscope (200 MHZ6 bandwidth, 2 GSample/s sampling rate). A 50- $\Omega$ coaxial cable was used to connect the Pearson monitor and the oscilloscope, this cable was terminated by a $50-\Omega$ resistive load.

A test cell, designed to house water-based dye solution and microbiological agar samples, was made of a Perspex cylinder (80-mm high) with an outer diameter of $150 \mathrm{~mm}$. The ends of the cylinder were covered by two PVC flanges. Inside this cylinder, a gramophone needle with a tip radius of $\sim 36 \mu \mathrm{m}$ was placed in a vertical holder fixed on the upper PVC flange, forming the $\mathrm{HV}$ electrode. The grounded electrode (an aluminium plate) was located on the lower PVC flange, inside the Perspex cylinder.

Liquid and microbiological (agar) samples were placed in two different types of sample holder, as shown in Figure 2. These sample holders were located on the grounded aluminium plate inside the Perspex container and subjected to $\mathrm{HV}$ discharges. Transparent, non-conductive, plastic plates $(55 \mathrm{~mm}$ diameter) were used for generation of interfacial discharges (Figure 2(a)); the same plates were lined with aluminium foil (Figure 2(b)) and used to generate discharges through the bulk of liquid samples. The volume of each liquid sample was $6 \mathrm{~m} \ell$, therefore the depth of liquid in the sample holders was only $\sim 2.4$ $\mathrm{mm}$. Agar samples were $\sim 2.5 \mathrm{~mm}$ thick.

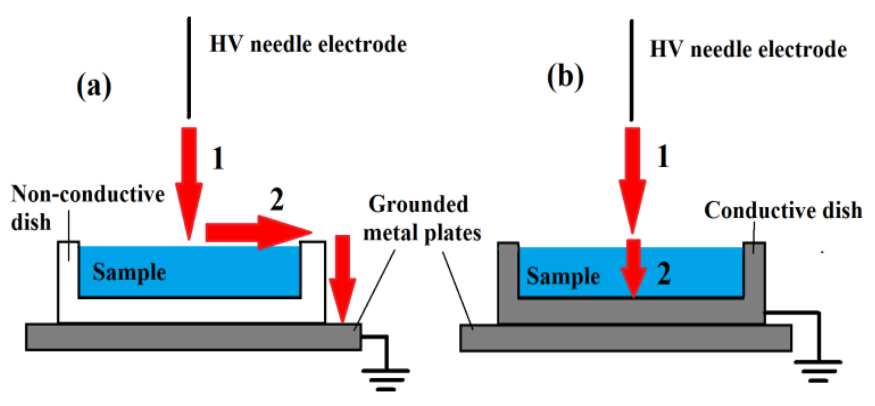

Fig. 2.Cross-sectional diagram of the sample dish held within the test cell (not to scale). (a) Non-conductive plastic dish; (b) plastic dish lined with aluminium foil (conductive dish). The arrows indicate the paths followed by the generated transient discharges: (1) vertical path through the air towards the sample surface; (2) interfacial path in the case of non-conductive sample holder (a), and path through the bulk of liquid sample in the case of the conductive sample holder (b).

When the non-conductive plastic dish was used, Figure 2(a), the discharge initiated at the tip of the needle HV electrode propagates vertically down towards the surface of the sample (path 1). The discharge continues its development across the sample/air interface towards the edge of the sample holder (path 2 ), before reaching the grounded metallic plate. In the case of conductive sample holders, Figure 2 (b), the transient discharge produced at the tip of the HV needle propagates vertically down towards the sample surface (path 1), and the ionic current closes the circuit by flowing through the bulk of the sample towards the grounded aluminium foil. Therefore, in the case of the nonconductive dish, a shorter path length is required to achieve the same breakdown voltage as in the case of the conductive sample holder, where the surface of the sample acts as a virtual ground.

During the tests, an air pump (VP 1HV, KNF Neuberger Ltd.) was used to supply a gentle air flow (flow rate was $5 \mathrm{l} / \mathrm{min}$ ) through the test cell, and the gas leaving the test cell was sent to an ozone analyzer. The air delivered to the test cell was 

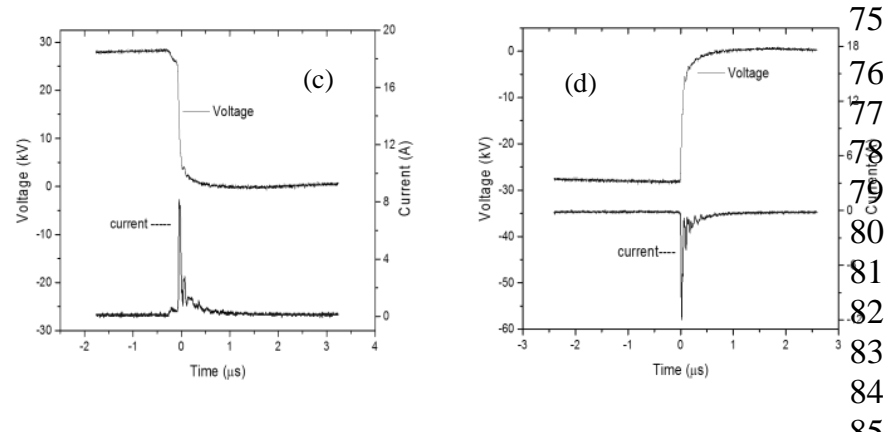
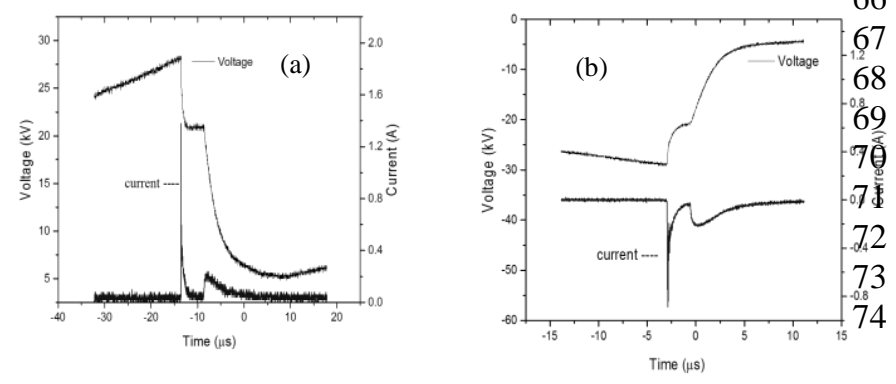

laboratory air at ambient temperature and humidity $\left(\sim 20^{\circ} \mathrm{C}, \sim 4 \Theta \Psi_{\circ}\right.$ relative humidity).

The $\mathrm{pH}$ of the liquid and the agar samples was measure 43 Instruments $\mathrm{PH} 210$ ) for the liquid samples, and using $\mathrm{pH} 45$ indicator strips (Johnson Universal $\mathrm{pH}$ 1-14) for the aga6 samples. The conductivity of the liquid samples was measure 47 using a conductivity meter (Hanna Instruments HI 933000), th 48 conductivity of the agar samples was measured in the test cel49 with two parallel electrodes using an AVOmeter model $8 \mathrm{Mk} \not \mathbf{0} 0$

The presence of transient discharges in the test cell was 1 detected by the collapse of the voltage waveform. Th52 maximum voltage before the voltage collapse is called th 53 breakdown voltage in this study. Figure 3 shows the voltage an $\mathbb{4}^{4}$ current waveforms in the cases of non-conductive an 55 conductive sample holders for water solution samples (similat 57 waveforms were obtained for agar samples). It can be seen thaf 8 in the case of non-conductive dishes (Figure 3(a) and (b)), \$9 double voltage collapse and two current peaks were observed for both polarities. This is indicative of the two-stage discharge propagation process discussed above: vertical transient discharges propagating towards the sample surface (path 1 in Figure 2(a)), and surface discharges (path 2 in Figure 2(a)). However, in the case of the conductive sample holder, only single voltage collapse event and a single current impulse wer 60 observed, Figure 3(c) and (d). These processes correspond t81 the direct vertical discharge propagation path shown in Figurg2 2(b), the current then dissipating via ionic conduction througb3 the bulk of the sample.

\section{4}

65

66

67

69

田

7 策

72

73

$$
4
$$
75 before and after plasma treatment, using a $\mathrm{pH}$ meter (Hann44

Fig. 3. Voltage and current waveforms for 2 different sample holders: ( $\$ 6$ $+28 \mathrm{kV}$ non-conductive dish; (b) $-28 \mathrm{kV}$ non-conductive dish; (c) $+28 \mathrm{kV}$ foil 87 lined conductive dish; (d), $-28 \mathrm{kV}$ foil-lined conductive dish.

The waveforms shown in Figure 3 are similar to transein $\$ 9$ spark discharge waveforms [19], [20]. A transient spare 0 discharge is characterised by the development of an initial 1 streamer and its transformation into a transient spark whic/2 manifests itself via the appearance of a high-current impulse. In 3 the case of transient sparks, the non-equilibrium plasma has a gas temperature in the range $500 \mathrm{~K}-1500 \mathrm{~K}$ [19], [20]. Thus, transient spark discharges differ from typical spark discharges in which significantly hotter plasma can be close to its local thermodynamic equilibrium. The plasma of transient spark discharges is highly reactive, such discharges producing $\mathrm{OH}$ radicals, ozone, excited ions, and atomic radicals and molecules [20], with application in chemical oxidation [21], and biodecontamination treatment [22].

The distance between the needle electrode and the sample surface was adjustable, and was used to obtain three different breakdown voltages: $20 \mathrm{kV}, 24 \mathrm{kV}$ and $30 \mathrm{kV}$. The distance between the HV needle electrode and the sample surface and corresponding breakdown voltages are shown in Table I.

TABLE I

Distances From The Tip Of The HV Needle Electrode To The SAMPLE SURFACE AND CORRESPONDING BREAKDOWN VOLTAGES

\begin{tabular}{ccccc}
\hline \hline \multirow{2}{*}{$\begin{array}{c}\text { Breakdown } \\
\text { voltage, } \mathrm{kV}\end{array}$} & \multicolumn{2}{c}{$\begin{array}{c}\text { Non-conductive } \\
\text { sample holder, mm }\end{array}$} & \multicolumn{2}{c}{$\begin{array}{c}\text { Conductive sample } \\
\text { holder, mm }\end{array}$} \\
& Positive & Negative & Positive & Negative \\
+20 & 0.5 & 0.7 & 4.9 & 1.7 \\
+24 & 5.1 & 1.4 & 7.7 & 3.3 \\
+28 & 7.3 & 3.7 & 11.1 & 6.0 \\
\hline \hline
\end{tabular}

As shown in Table I, the distance from the HV needle electrode to the sample surface to achieve the same breakdown voltage is much shorter for the non-conductive sample holders as compared with the conductive sample holders. This is due to the longer total discharge path in the case of the non-conductive sample holders as compared with the conductive dishes. Also, Table I shows that a shorter distance from the negativelyenergised HV electrode to the sample surface is required in order to achieve the same breakdown voltage as for positive impulses. This reduction in the distance is required to compensate for the higher breakdown voltage of atmospheric air in the case of a negatively-energised sharp HV electrode, which is due to the electronegativity of air.

\section{OXIDATION CAPABILITY OF TRANSIENT DISCHARGES}

The oxidation capability of the impulsive atmospheric discharges generated was studied using indigo carmine dye $\left(\mathrm{C}_{16} \mathrm{H}_{8} \mathrm{~N}_{2} \mathrm{Na}_{2} \mathrm{O}_{8} \mathrm{~S}_{2}\right.$, Sigma Aldrich Ltd) as a chemical probe. Samples of aqueous indigo carmine solution were treated in non-conductive and conductive sample holders, and their optical transmittance was measured. The chemical species produced by the transient discharges can react with the dye and can convert indigo carmine molecules into isatin-5-sulfonic acid, resulting in the decolourisation effect. The difference in the optical transmittances of the treated and untreated samples allows a reduction in the dye concentration to be obtained. This reduction is an indicator of the chemical oxidation capability of the transient discharges, as the change in transmittance is a result of disintegration of chromogenic bonds in indigo carmine dye [23]. The optical transmittance of the dye solutions was obtained using a UV-Visible spectrophotometer (Biomate, Thermo-Spectronics Europe). Section III-A presents the results of the investigation into the oxidation effects of the surface 
1 transient discharges which propagate along the sample/aił3 2 interface (samples were treated in the non-conductive sample4 3 holders), and Section III-B presents the oxidation result45 4 obtained in the case of the direct discharges (treatment in th $₫ 6$ 5 conductive sample holders).

A. Oxidation capability of the surface transient discharges 48

An indigo carmine aqueous solution with a dye concentratioft 9 of $0.25 \mathrm{~g} / \ell$ was prepared using distilled water. A $5-\mathrm{m} \ell$ sample 0 of this solution was transferred to the non-conductive sampla 1

10 holder using a pipette. The sample holder was placed on the to 2

11 of the metallic grounded plate inside the Perspex container an 3

12 exposed to plasma discharges for four different treatment times 4

13 (1, 3, 5 and $7 \mathrm{~min})$ and for impulses of both polarities, all at 265

14 pps. During the treatment, the Perspex container was flushe 66

15 with ambient air, which then passed through the ozone analyse.5.7

16 The ozone levels in all tests were lower than $1 \mathrm{ppm}$. After each 8

17 exposure, the optical transmittance of the sample was measure 99

18 along with that of an unexposed control sample. The differentia 90

$$
T=\frac{T_{b}}{T_{a}} \cdot 100 \%
$$

where $T_{a}$ is the transmittance of the unexposed sample, and $T_{b 8}^{67}$ is the transmittance of treated sample. Examples of the differential transmittance spectra for the dye samples treated for different time intervals are shown in Figure 4.

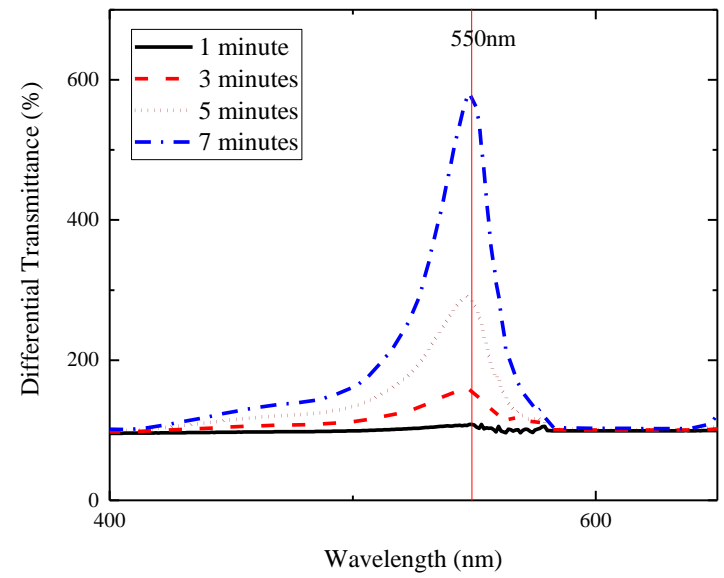

Fig. 4. Differential optical transmittance of indigo carmine aqueous solution 88 treated with surface discharges at $+28 \mathrm{kV}$ and untreated (control) solutions. 89 Lambert law, the concentration of indigo carmine in water wa92 obtained. The results of this analysis are shown in Figure 5; thi $\$ 3$ graph represents a normalised concentration of the dye in wate 4 as a function of the total charge delivered during the plasma5 treatment, normalised by the surface area of the sample holder 6

The normalised charge (dose) was selected in this study to represent the oxidation capability of the transient plasma discharges. In the present study, the water-dye solutions and agar samples were treated with direct positive and negative plasma discharges in air. Therefore, the liquid and agar samples were subjected to the action of both charged and neutral chemial
Using the differential optical transmittance and the Beer191 species generated by the transient plasma discharges. Such direct exposure is considered to be more efficient for biodecontamination as compared with exposure of bio-samples to the plasma afterglow by locating these samples outside the direct discharge zone [24]. It is known that the charged particles produced by the plasma discharges are responsible for the generation of chemically-active neutral species and direct chemical oxidation [13], [25].

Generation of charged particles (electrons, ions and clusters) in the discharge leads to the appearance of electric current in the circuit. The electrons and ions are involved in the formation of neutral chemical species, therefore it can be assumed that the current is a parameter which provides information not only on the presence of charged particles, but also correlating with the total amount of newly-developed chemical species. The charged, chemically-active species include nitrites, nitrates and oxygen anions which are negatively charged; positivelycharged species include protons, oxygen ions and positivelycharged $\mathrm{NO}_{\mathrm{x}}$ species. The neutral activated species include both reactive oxygen species (ROS) and reactive nitrogen species (RNS). Amongst the neutral ROS are singlet oxygen, ozone, hydrogen peroxide and hydroxyl radicals; neutral RNS include nitric oxide and nitrogen dioxide. A detailed description of the chemical processes involved in formation of neutral and charged species can be found in [24] and [25].

It was established in [27] that in the case of corona discharges in ambient air, the "electrical" parameters which control the sample's treatment area and the flux of neutral activated species are the voltage, the current and the exposure time. Moreover, it was found that in the case of fixed electrical parameters, the $\mathrm{pH}$ of water treated with corona discharges generated by a HV electrode located above the water surface in air is a linear function of the exposure time [27].

The results obtained in this study, Figure 5, demonstrate that the variation in voltage does not significantly affect the bioinactivation and oxidation processes. Also, in this study, the distance between the HV electrode and the sample surface was variable, therefore different proportions of energy may be dissipated in the plasma above the sample. Therefore, it is reasonable to introduce the total normalised charge (dose) as a parameter which can be used for description of the kinetics of the plasma treatment process. It is expected that the dosedependent kinetic relationships will depend upon the disharge regime. The total charge in the present tests was calculated by integration of the experimentally-obtained current waveforms, and the dose was obtained by dividing the total charge by the surface area of the sample plate. This normalisation was done for both cases, surface and direct discharges. Although in the case of direct discharge treatment the actual cross-section of plasma interaction with the sample surface is smaller than in the case of surface discharges, this normalisation procedure helps to compare the efficacy of both types of plasma discharge in the present experimental conditions. 

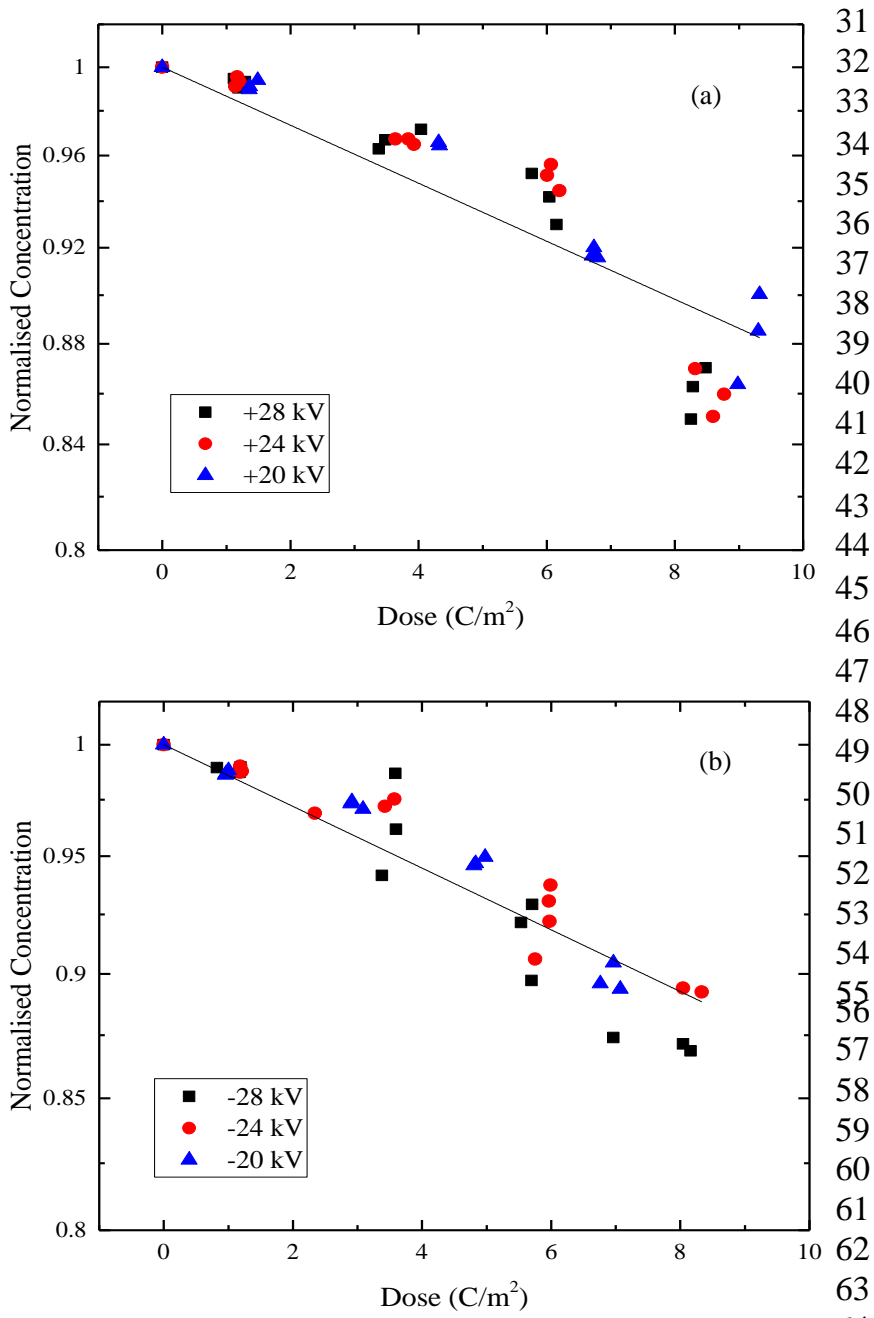

Fig. 5. Concentration of indigo carmine as a function of the dose after treatme 65 with: (a) positive surface discharges; (b) negative surface discharges. Soli66 lines, fitting by (3): (a) $\mu=0.013 \mathrm{~m}^{2} / \mathrm{C}$ and (b) $\mu=0.014 \mathrm{~m}^{2} / \mathrm{C}$.

31 32 33 34
35

The normalised dose-dependent concentration, $K(D)$, wa 89 obtained by (2):

$$
K(D)=C(D) / C_{0}
$$

where $C(D)$ is the actual concentration of the dye in wate $(\mathrm{mg} / \ell), C_{0}$ is the initial concentration of the dye $(250 \mathrm{mg} / \ell$ in 5 the present study), and $D$ is the dose $\left(\mathrm{C} / \mathrm{m}^{2}\right)$.

It is known from literature that time of plasma exposure can b 97 used as an independent parameter for descripton of the 8 decolorisation kinetics and a time-dependent (pseudo) first9 order kinetic process was used in the analysis of the plasma decolourisation rates of different water-soluble dyes subjecteg to pulsed dielectric barrier discharges [28], spark discharge [29] and glow discharges [30]. However, in the case of transient 33 plasma regimes, it is important to consider not only time but 3 also the total delivered charge. The area-normalised charge was therefore selected as an independent parameter for the kinetic 66 analysis in the present paper.

Figure 5 shows the normalised concentration of the dye as 87 function of the dose for positive and negative discharges (for af 8 tested voltages). It was found that the concentration of indig 89 carmine in water reduces with an increase in the dose. The dye concentration is a function of the dose only and does not depend on the breakdown voltage. The change in the normalised concentration of the dye is relatively small, $\sim 15 \%$, and it is problematic to establish the exact functional behavior of $K(D)$ : for example, several different functions can be used to fit the experimental data in Figure 5. To provide a quantitative comparison of the oxidation capability of the discharges, an exponential fitting function (3) was used, and this approach is consistent with the description of the decolourisation kinetic processes provided in [28], [30]:

$$
K(D)=\exp (-\mu D)
$$

where $\mu$ is the dose-dependence of the decolourisation process $\left(\mathrm{m}^{2} / \mathrm{C}\right)$. Values for $\mu$ have been obtained using the fitting procedure in Origin Pro 8 graphing software package, and found to be $0.013 \mathrm{~m}^{2} / \mathrm{C}$ and $0.014 \mathrm{~m}^{2} / \mathrm{C}$ for the positive and negative discharges, respectively. The analytical fitting lines were plotted using the obtained values of $\mu$, and these analytical lines are shown in Figure 5. Note that the normalised concentration axes in Figs. 5 and 6 are logarithmic. Thus, this analysis shows that the oxidation capability of surface discharges is similar for both positive and negative polarities.

\section{B. Oxidation capability of direct discharges}

The oxidation effects of direct transient discharges that propagate through the bulk of the sample were investigated. As with the surface discharges, a 6-ml sample of indigo carmine aqueous solution was placed into a conductive sample holder which was located on the top of the grounded aluminum electrode. The samples were again treated with impulsive discharges, under the same experimental conditions described in Section III-A. The differential transmittance of the treated and control samples obtained at $550 \mathrm{~nm}$ was used for calculation of the dye concentration. The results of this analysis are shown in Figure 6, which represents the normalised dye concentration obtained by (2) as a function of the dose, $D$, for direct positive and negative discharges.

The electrical conductivity and $\mathrm{pH}$ of the water-dye solutions were measured before and after plasma treatment. For both types of treatment, surface discharge and direct discharge treatment, an increase in the electrical conductivity of the solutions was observed. However, this increase was not significant, the initial conductivity being $\sim 0.11 \mathrm{mS} / \mathrm{m}$, and the largest change observed being for negative direct streamer discharge treatment, where the conductivity increased to $\sim 0.15 \mathrm{mS} / \mathrm{m}$. In all treatment cases, a decrease in $\mathrm{pH}$ of the water-dye solutions was observed, the $\mathrm{pH}$ decreasing from $\sim 5.5$ to a minimum value of $\sim 3.5$ for surface discharge treatment, and to 3.5 - 4 for direct discharge treatment. A decrease in $\mathrm{pH}$ of water-dye solutions after plasma treatment was also observed in [16].

As in the case of surface discharges, the dye concentration is a dose-dependent parameter only, this concentration decreases with an increase in the dose. The decolourisation process can be described by function (3). Values of $\mu$ have been obtained using the fitting procedure in Origin Pro 8 graphing software package, and found to be $0.019 \mathrm{~m}^{2} / \mathrm{C}$ and $0.012 \mathrm{~m}^{2} / \mathrm{C}$ for the 
1 positive and negative discharges, respectively. Thus, thB0 2 positive direct discharges resulted in a higher decolourisation 1 3 rate as compared with the negative discharges, also this rate i32 4 higher than the decolourisation rate achieved by the surfack3 5 discharges.

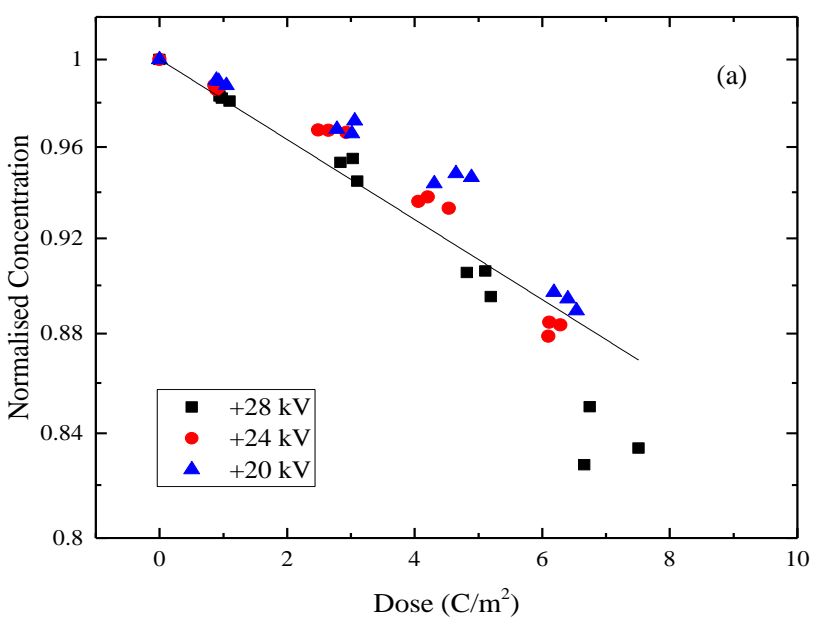

7

8

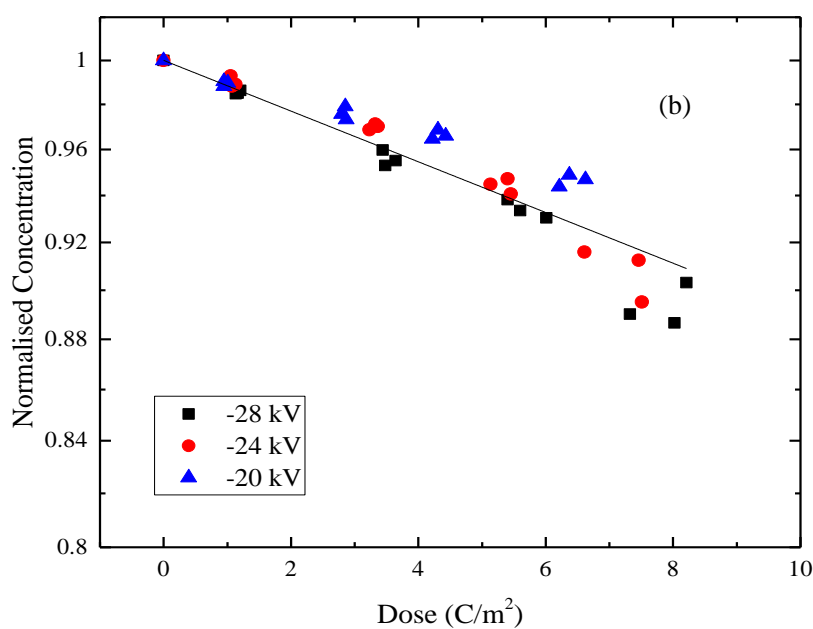

10 Fig. 6. Concentration of indigo carmine as a function of the dose after treatment 52 11 with: (a) positive direct discharges; (b) negative direct discharges. Solid lines, 12 fitting by (3): (a) $\mu=0.019 \mathrm{~m}^{2} / \mathrm{C}$ and (b) $\mu=0.012 \mathrm{~m}^{2} / \mathrm{C}$.

\section{BIO-DECONTAMINATION EFFECTS OF TRANSIENT DISCHARGES}

This section is focused on investigation of the biodecontamination effects of the atmospheric plasma discharges which propagate across the sample/air interface and through the bulk of the samples. Again, two different sample holders (nonconductive and conductive) were used to produce the surface and direct discharges. These sample holders were filled with nutrient agar and microorganisms were seeded onto this waterbased agar. The agar-filled bio-contaminated plates were located in the test cell under the HV needle electrode and treated with impulsive discharges of both polarities. The breakdown voltages, treatment time intervals and the pulse repetition rat 53 used in this study were the same as in Section III. Two types of 5 bacteria were selected for the bio-decontamination study56 Gram-negative E. coli and Gram-positive S. aureus. These microorganisms were grown in 100-ml nutrient broth and incubated under rotary conditions $(120 \mathrm{rpm})$ at $37^{\circ} \mathrm{C}$ for 18 hours. Bacterial cultures were then centrifuged $(3939 \times \mathrm{g}$ for 10 min) and cells resuspended and serially diluted in phosphate buffered saline (PBS) to make bacteria suspensions with a population density of $10^{3}$ colony forming units (CFU) per $\mathrm{ml}$. Agar was prepared in non-conductive and conductive sample holders, $100 \mu \mathrm{l}$ of bacteria suspension was evenly spread on the agar surface using an L-shaped spreader, providing a seeding population on the agar surface of 100-200 CFU/plate. After 40 exposure to the positive or negative discharges for $1,3,5$ and 7 $41 \mathrm{~min}$ (20 pps pulse repetition rate), the exposed samples were 42 incubated at $37^{\circ} \mathrm{C}$ for $24 \mathrm{~h}$ and then enumerated.

\section{A. Inactivation by surface transeint discharges}

Microbiological samples were exposed to the positive and negative discharges in the non-conductive sample holders, which ensure their interfacial propagation path across the agar/air interface. Following enumeration of the surviving bacteria, inactivation curves were plotted: the normalised population, $S(D)$, is presented as a function of the dose, $D$.
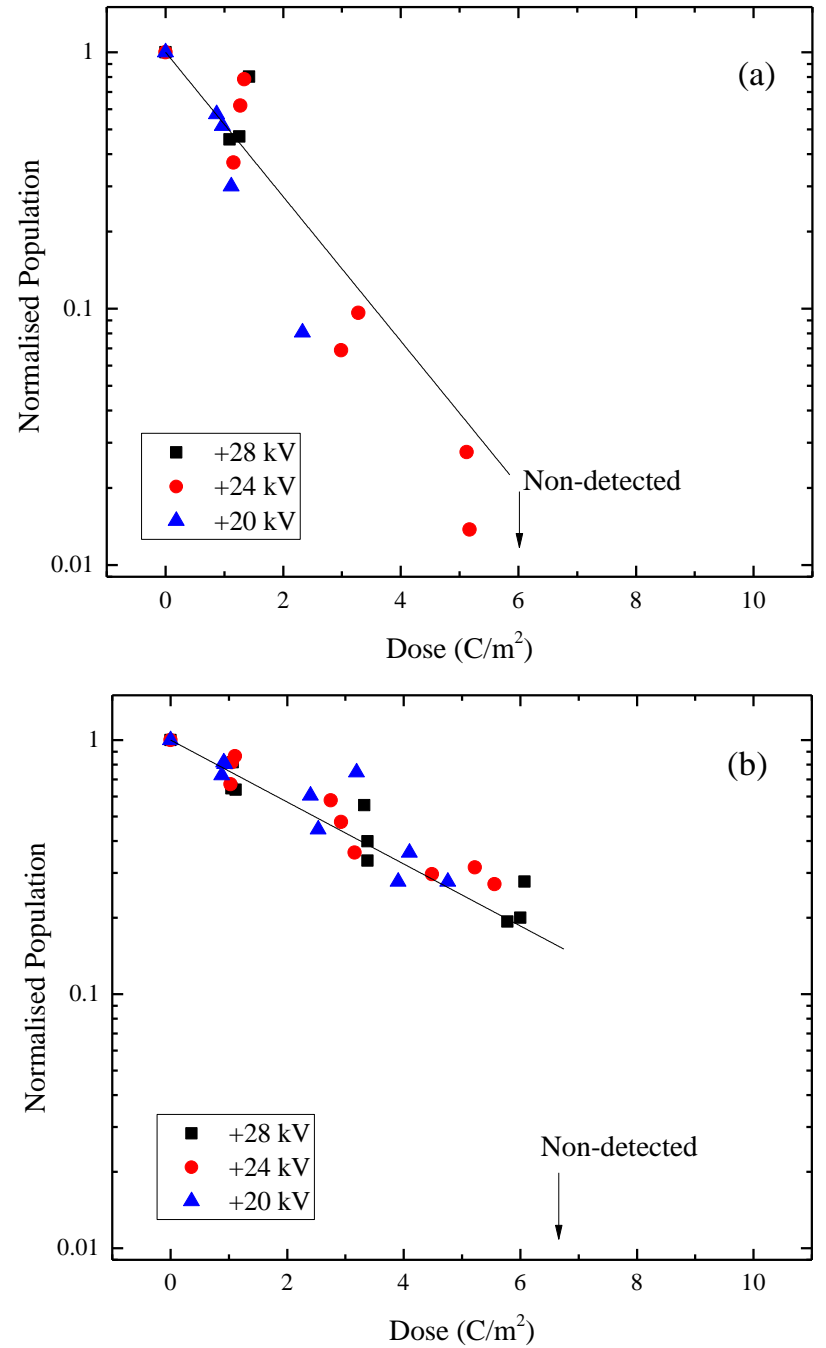

Fig. 7. Normalised surviving population of (a) E. coli and (b) S. aureus, after exposure to positive surface discharges. Solid lines, fitting by (5): (a) $\lambda=0.648 \mathrm{~m}^{2} / \mathrm{C}$ and (b) $\lambda=0.281 \mathrm{~m}^{2} / \mathrm{C}$.

[Type text] 


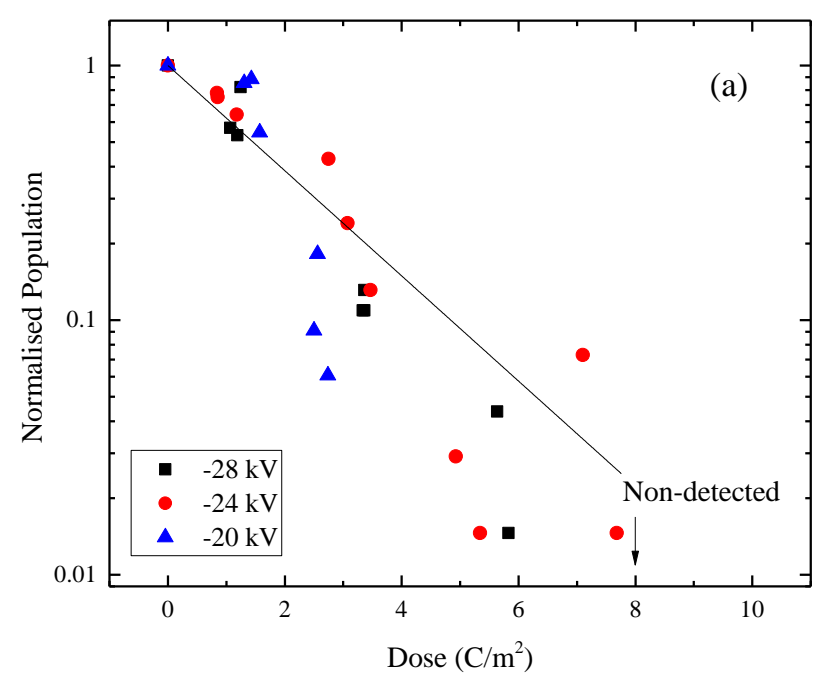

18

19

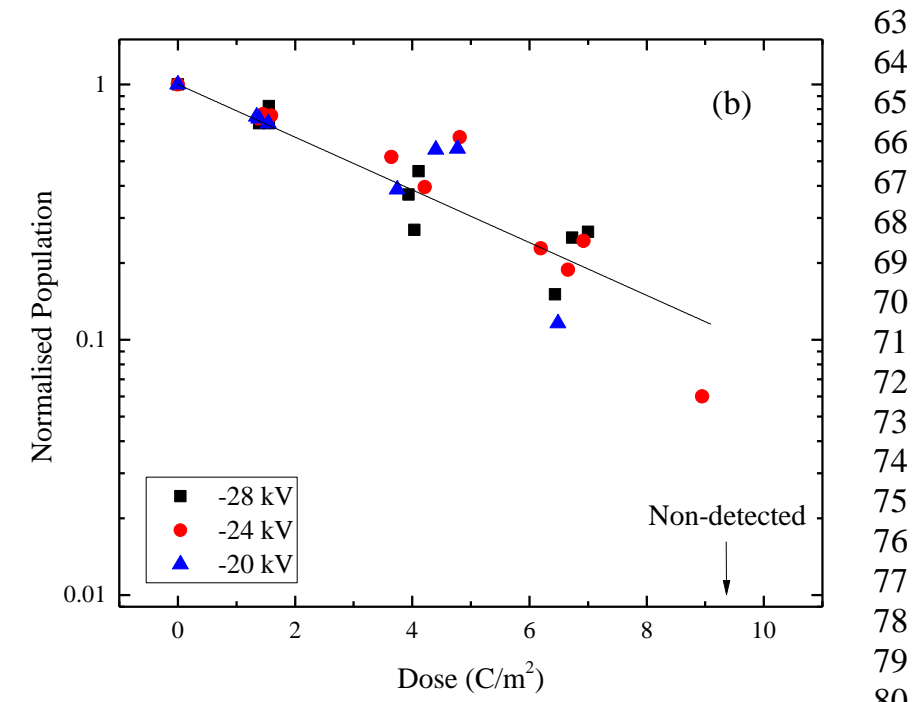

The dose-dependent population of microorganisms was9 obtained using (4) for each test:

$$
S(D)=P(D) / P_{0}
$$

where $P(D)$ is the actual surviving bacterial population, $P_{0}$ is 4 the initial population of bacteria and $D$ is the dose $\left(\mathrm{C} / \mathrm{m}^{2}\right)$.

The normalised population as a function of the dose can b36 fitted with a pseudo first-order kinetic function (5) for all tested7 voltages and for both types of microorganisms:

$$
S(D)=\exp (-\lambda D)
$$

where $\lambda$ is the dose-dependence of the inactivation proces 42 $\left(\mathrm{m}^{2} / \mathrm{C}\right)$.

Fig. 8. Normalised surviving population of (a) E. coli and (b) S. aureus, after exposure to negative surface discharges. Solid lines, fitting by (5): (a) $\lambda=0.476 \mathrm{~m}^{2} / \mathrm{C}$ and (b) $\lambda=0.238 \mathrm{~m}^{2} / \mathrm{C}$.

Figure 7 shows the normalised surviving fraction, $S(D)$, of E. coli and $S$. aureus treated by surface discharges as a function of the dose. As the normalised population in this figure is shown in a semi-log scale, the vertical lines labeled "non-detected" indicate doses at which no CFU was detected in the majority of sample dishes after the treatment. The fitting procedure was implemented in Origin Pro 8 graphing software and the

31 analytical fitting lines are shown in Figure 7. Values of $\lambda$ were

32 found to be $0.648 \mathrm{~m}^{2} / \mathrm{C}$ and $0.281 \mathrm{~m}^{2} / \mathrm{C}$ for $E$. coli and $S$. aureus, 3 respectively. These inactivation rates confirm that $E$. coli is substantially more sensitive to the plasma treatment than S. aureus.

Figure 8 shows the normalised population, $S(D)$, of $E$. coli and $S$. aureus as a function of the dose in the case of negative surface-discharge treatment. As in the case of positive surface39 discharge treatment (Figure 7), Figure 8 demonstrates that 40 inactivation by negative surface discharges depends only on the 41 dose, and is almost independent of the breakdown voltage. The experimental data in Figure 8 were fitted with the exponential function (5), and this fitting confirms that the inactivation process can be described by a pseudo first-order kinetic. The 45 fitting procedure was implemented using Origin Pro 8 graphing 46 software and the rates of inactivation, $\lambda$, were found to be 0.476 $47 \mathrm{~m}^{2} / \mathrm{C}$ for $E$. coli and $0.238 \mathrm{~m}^{2} / \mathrm{C}$ for $S$. aureus. Again, these 48 results confirm that $E$. coli is more sensitive to the plasma 49 50 51 52

\section{$\left(0.140 \mathrm{~m}^{2} / \mathrm{C}\right)$.}

\section{B. Inactivation by direct transient discharges}

The inactivation kinetics of E. coli and $S$. aureus were also studied using direct transient discharges: discharges which propagate through the bulk of the agar sample. To provide such a discharge path, aluminium foil lined sample holders were used. The results of this study allow for a comparison between the inactivation capabilities of surface and direct transient discharges to be made.

Microorganisms were seeded onto agar which was placed on the conductive sample holders and exposed to the transeint discharges generated by the same voltages as in Section IV-A. In the case of the direct discharges, the cross-sectional contact area between the direct plasma channel and surface of the sample is (visually) small. However, the activated species produced by the transient plasma on and above the agar surface can move across the surface of the agar and reach the periphery of the plate, in the present tests the effects of the discharge on the bacteria were observed at the edges of the sample holders. After the direct discharge treatment, enumeration of the surviving microorganisms was conducted.

Figure 9 shows the normalised population of E. coli and $S$. aureus as a function of the dose, $S(D)$, after exposure to positive direct discharges. The experimental inactivation data presented in Figure 9 were fitted with the pseudo first order kinetic function (5). As in the case of the surface discharges, $S$. aureus demonstrated a higher degree of resistance to the plasma treatment; the rate of inactivation of $E$. coli $\left(0.311 \mathrm{~m}^{2} / \mathrm{C}\right)$ is more than double the rate of inactivation of $S$. aureus

[Type text] 


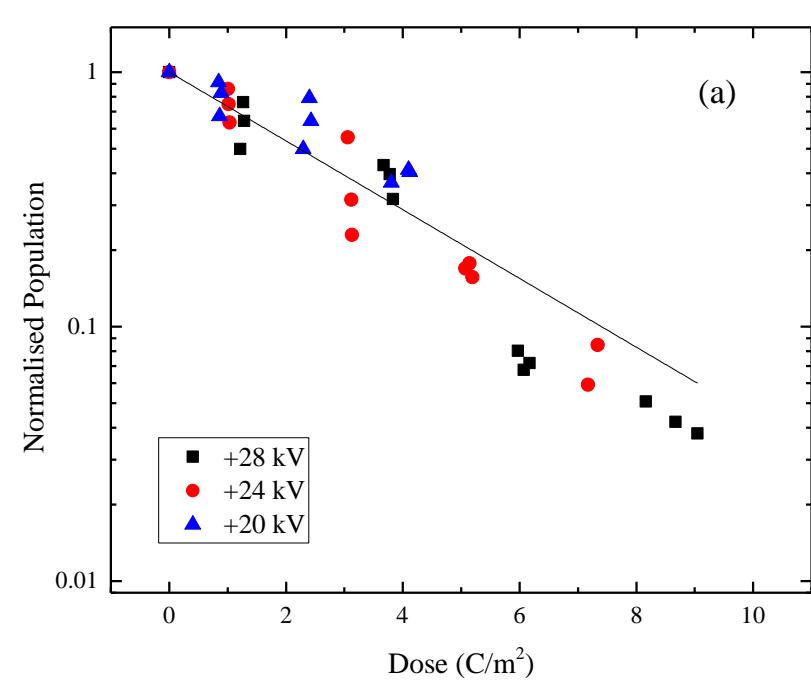

1

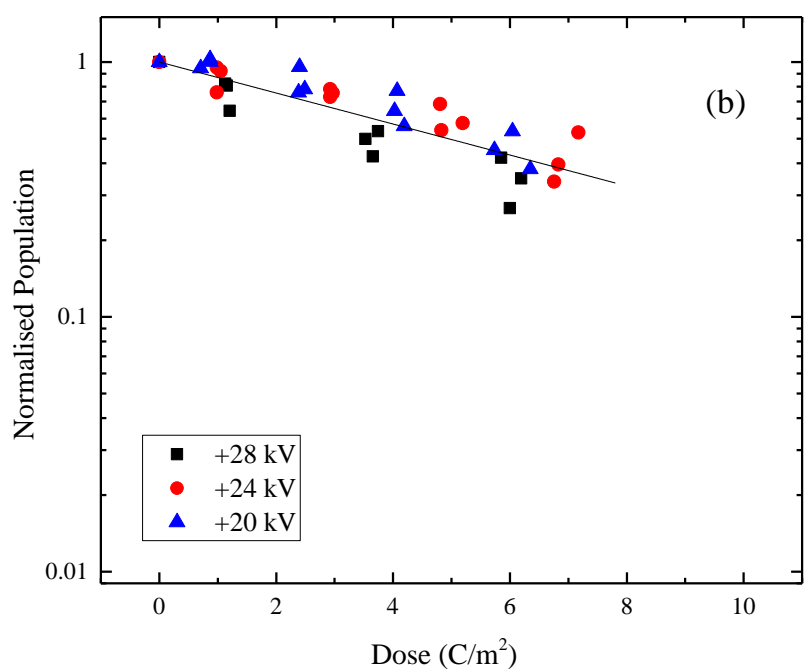

Fig. 9. Normalised surviving population of (a) E. coli and (b) S. aureus, after 45 4 exposure to positive direct discharges. Solid lines, fitting by (5): (25 $\lambda=0.311 \mathrm{~m}^{2} / \mathrm{C}$ and (b) $\lambda=0.140 \mathrm{~m}^{2} / \mathrm{C}$

The results of the inactivation tests using negative direct discharges are represented in Figure 10. This figure shows 28 normalised surviving population as a function of the dose, $S(D) 29$ and the experimental data were fitted with the pseudo first-ordes 0 1 kinetic equation (5). The fitting procedure was implemented iB1 12 Origin Pro 8 graphing software, and the inactivation rates fo 2 13 both microorganisms were obtained: again, the rate os3 14 inactivation of E. coli $\left(0.16 \mathrm{~m}^{2} / \mathrm{C}\right)$ was found to be more than 4 15 2-fold higher than the rate of inactivation of S. aureus $(0.065$ $\left.16 \mathrm{~m}^{2} / \mathrm{C}\right)$.

17 It can be seen that the negative direct transient discharge37 18 demonstrated lower inactivation capability for botis 19 microorganisms as compared with the positive direct discharges.9
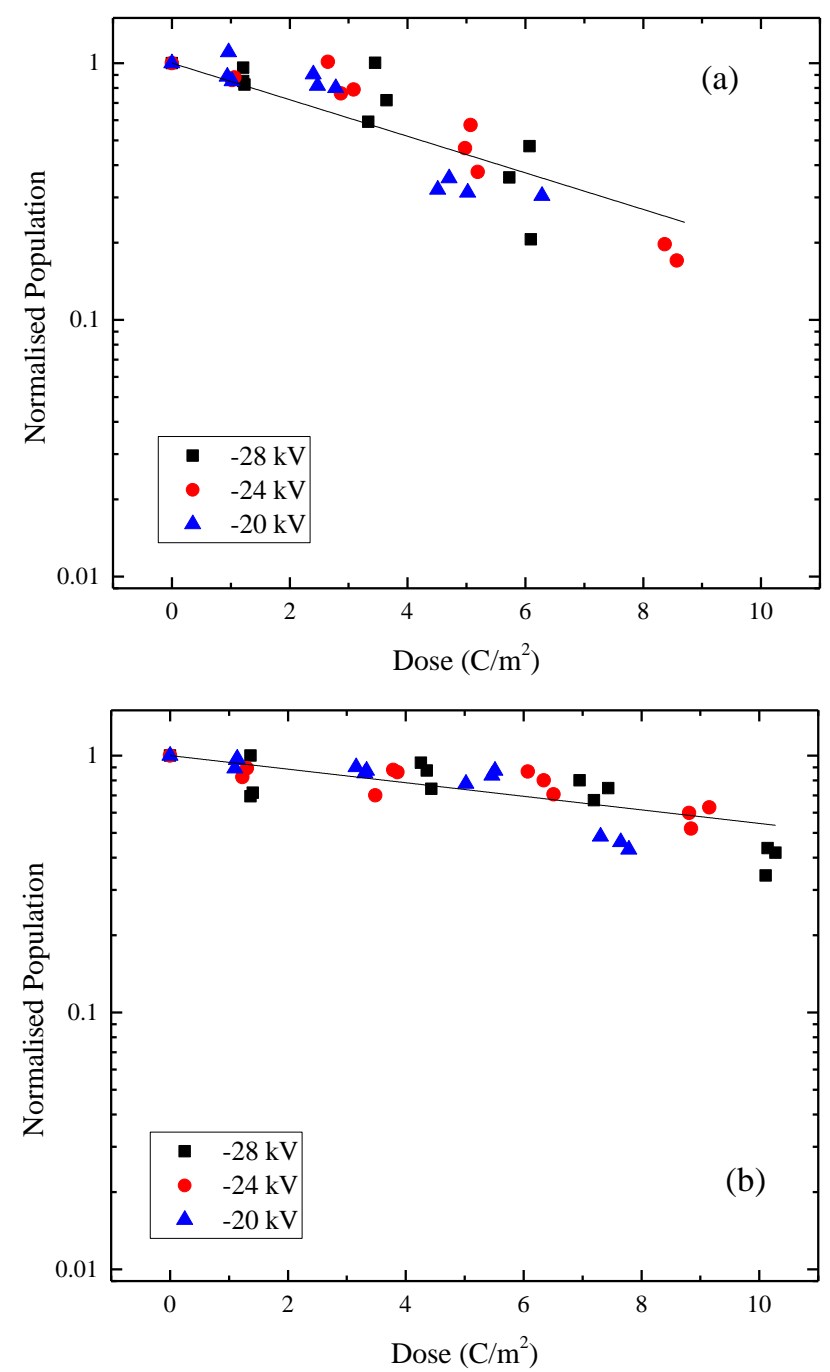

Fig. 10. Normalised surviving population of (a) E. coli and (b) S. aureus, after exposure to negative direct transient discharges. Solid lines, fitting by (5): (a) $\lambda=0.164 \mathrm{~m}^{2} / \mathrm{C}$, and (b) $\lambda=0.061 \mathrm{~m}^{2} / \mathrm{C}$.

\section{DISCUSSION \& CONCLUSIONS}

The main objective of this paper was to investigate the oxidation and decontamination effects of surface and direct impulsive atmospheric discharges. This study helps to answer the important question: which type of transient plasma discharge (TAP) is more efficient for chemical oxidation and microbiological decontamination? The results of this study can be used in further optimisation of the energisation parameters of the impulsive discharges and of the topologies of plasma treatment reactors for different practical applications, as is now discussed. It has been confirmed in this study that impulsive transient discharges produce significant oxidation and decontamination effects, which is in line with previously41 published results [22], [31], [32]. Transient discharges of both 42 polarities, with different peak voltage levels, were able to 43 reduce the concentration of the dye in water and to inactivate 44 microorganisms on agar surfaces. It has been shown that 45 although both, surface and direct transient discharges resulted 46 in chemical oxidation and microbiological decontamination, 
1 there was a noticeable difference in the rates of these processe 49

2 for these two types of discharge.

Table II summarises the decolourisation rates obtained in thi 1 study: it can be seen that in the case of surface transien 2 discharges, the difference in the decolourisation rates fo 53 6 positive and negative energisation is less than $10 \%$. Howeven 4 7 positive direct discharges resulted in a higher decolourisation5 8 efficacy as compared with negative direct discharges: th 66 9 difference between these two decolourisation rates is $\sim 37 \%$. 57

13
TABLE II.

DECOLORISATION RATE $\left(\mathrm{m}^{2} / \mathrm{C}\right)$ FOR SURFACE AND DIRECT DisCHARGES

\begin{tabular}{c|c|c|cr}
\hline \multicolumn{2}{c}{ Surface discharge } & \multicolumn{2}{c}{ Direct discharge } & 60 \\
\hline pos & neg & pos & neg & 61 \\
\hline 0.013 & 0.014 & 0.019 & 0.012 & 62 \\
$(0.012-0.014)$ & $(0.013-0.015)$ & $(0.018-0.20)$ & $(0.011-0.013)$ & 63 \\
\hline \multicolumn{4}{c}{ "Pos" for positive energisation, "neg" for negative energisation } & 64 \\
\multicolumn{4}{c}{ Values in brackets indicate a 95\% confidence interval. } & \multicolumn{4}{c}{65}
\end{tabular}

The maximum energy efficiency of the decolourisation of the 66 indigo carmine dye obtained in the present work is $\sim 5 \mu \mathrm{mol} / \mathrm{k} \mathrm{9}^{7}$ for positive direct discharges. This value is higher than the 68 efficiency of decolourisation of the indigo carmine dy 69 achieved in [33], which is $3.7 \mu \mathrm{mol} / \mathrm{kJ}$ for the dye concentration 0 of $0.05 \mathrm{~g} / \ell$. This concentration is 5 -fold lower than the 1 concentration used in the present work, $0.25 \mathrm{~g} / \ell$. It was als ${ }^{2}$ shown that the efficiency of decolourisation of the indig ${ }^{3}$ carmine dye increases with an increase in the initial 4 concentration of the dye in water [33]. The initial 5 concentrations tested in [33] were in the range between $0.01 \mathrm{~g} / \ell^{6}$ to $0.05 \mathrm{~g} / \ell$. However, no experimental data is provided for 7 higher concentrations.

The biological inactivation capability of impulsive 79 discharges has been also investigated in this paper. E. coli an 80 S. aureus were used as model Gram-negative and Gram- 81 positive microorganisms, respectively. The inactivation results 2 demonstrated the strong bactericidal effects produced by both 3 surface and direct discharges. In the decontamination tests, a 84 surviving colony forming units on the whole plate surface were 85 counted in order to obtain the inactivation rate. Therefore, thi $\$ 6$ quantitative approach does not take into account non- 87 uniformities in decontamination on the plate surface, for 88 example the most significant decontamination effect on the agar 89 surface was obtained directly under the HV needle, however 90 decontamination effect was also observed at the edges of the 1 plate surface. Table III summarises the inactivation rates ${ }^{2}$ obtained in the present study.

TABLE III.

INACTIVATION RATE $\left(\mathrm{m}^{2} / \mathrm{C}\right)$ FOR SURFACE AND DIRECT DISCHARGES 96 \begin{tabular}{c}
\multicolumn{3}{l}{ Surface discharge } \\
\hline E.coli
\end{tabular}

It was established that the inactivation capability of direxc6 6 discharges is substantially lower than that of surface discharge997 the inactivation rates associated with direct discharges are $~ 2-$ fold lower than the inactivation rates of surface dischares, for both microorganisms, and for both polarities. In the case of the non-conductive sample holders, the surface discharges treat a larger surface area as compared with the direct discharges (treatment in the conductive sample holders). As microorganisms were seeded onto agar surfaces, the treatment with surface discharges resulted in a higher degree of inactivation for the same dose as compared with the direct transient discharges. Thus, the surface discharges demonstrated substantially higher bio-decontamination rates. However, even in the case of direct discharges, transient plasma result in a notable reduction of the bacterial population on the agar surfaces. As in the case of dye solutions, the electrical conductivity and $\mathrm{pH}$ of agar was measured before and after plasma treatment. It was found that, as in the case of dye solutions, the conductivity of agar increased. However, this increase was not negligible, the maximum change being observed for negative surface treatment: the electrical conductivity of agar before plasma treatment was $\sim 1.1 \mathrm{mS} / \mathrm{m}$, and the conductivity after such plasma treatment increased up to $\sim 1.5 \mathrm{mS} / \mathrm{m}$.

Using $\mathrm{pH}$-sensitive strips, it was found that there was a change in $\mathrm{pH}$ of the agar beneath the HV needle electrode. The radius of the spot of the agar surface which differed from the initial $\mathrm{pH}$ value was $\sim 3 \mathrm{~mm}$. However, no change in $\mathrm{pH}$ was observed outside this localised spot on the agar surface $(\mathrm{pH}$ value was $\sim 7$ ). This change in $\mathrm{pH}$ on the agar surface beneath the point $\mathrm{HV}$ electrode depends on the polarity of the $\mathrm{HV}$ impulses. For positive impulses, an increase in $\mathrm{pH}$ was registered (up to $\sim 8$ based on analysis of the colour of the strip). For negative impulses, a decrease in $\mathrm{pH}$ was registered, down to $\sim 5$ based on analysis of the colour of the strips. This increase in $\mathrm{pH}$ on the agar surface may be a result of the chemical action of cations produced by positive discharges - this suggestion is supported by the results obtained in [27], where it was found that the cations produced by positive corona discharges in air above the water surface resulted in an increase in the $\mathrm{pH}$ of water. Therefore, the observed difference in $\mathrm{pH}$ tendencies may help to explain the higher inactivation and decolourisation rates for positive direct discharges obtained in the present study. However, further investigation into $\mathrm{pH}$ variations due to transient plasma discharges of both polarities is needed to provide more detailed information on the role of $\mathrm{pH}$ changes in plasma-induced inactivation and bio-decontamination processes.

The higher decontamination efficiency for positive transient spark discharges was reported in [22], where S. typhimurium in water was treated with transient spark discharges, and it was found that positive transient sparks provided higher decontamination efficiency as compared with negative transient sparks. However, in the case of chemical oxidation capability, it was reported that the removal efficiency of cyclohexanone by the transient plasma spark discharges was $\sim 50 \%$ for both polarities of transient spark discharges [19]. Further investigation is required to enable a more-detailed analysis of the bio-decontamination and chemical oxidation efficacies of transient atmospheric plasma discharges.

Also, it was found that $E$. coli has a higher sensitivity to both types of plasma discharge than $S$. aureus: the inactivation rates

[Type text] 
obtained for E. coli are more than 2-fold higher than the्स 0 inactivation rates for $S$. aureus. This result can potentially b 71 explained by the structural difference between Gram-negativ 93 and Gram-positive bacteria: the thicker peptidoglycan layer of 4 Gram-positive bacteria may help to protect their cells from th 75 lethal damage caused by transient discharges.

The results obtained in this study will help in the furthey 77 understanding of the oxidation effects and microbiologicat 9 inactivation capability of impulsive atmospheric discharges 80 These results may be used in potential design and optimisatio 1 of plasma treatment systems based on transient discharges ig3 atmospheric air.

\section{REFERENCES}

[1] L. A. Rosocha, "Nonthermal Plasma Applications to the Environment88 Gaseous Electronics and Power Conditioning," IEEE Trans. Plasma Sci, vo89 33 , no. 1 , pp. $129-137,2005$.

[2] A. Mizuno, "Industrial applications of atmospheric non-thermal plasma i 1 environmental remediation," Plasma Phys. Control. Fusion, vol. 49, pp. A192 A15, 2007. [3] B. Haertel, T. Von Woedtke, K. Weltmann, and U. Lindequist, "Nor 94 Thermal Atmospheric-Pressure Plasma Possible Application in Woun 95 Healing," Biomol Ther, vol. 22, no. 6, pp. 477-490, 2014.

[4] R. Ono and T. Oda, "Optical Diagnosis of Pulsed Streamer Discharge und 97 Atmospheric Pressure 1 2," Int. J. Plasma Environ. Sci. Technol., vol. 1, no. 9,8 pp. 123-129, 2007. [5] W. F. L. M. Hoeben, E. M. van Veldhuizen, W. R. Rutgers, and G. M. 100 Kroesen, "Gas phase corona discharges for oxidation of phenol in an aquedil1 solution," J. Phys. D Appl. Phys., vol. 32, pp. L133-L137, 1999. [6] Z. Buntat, I. R. Smith, and N. . A. . Razali, "Ozone Generation by Pulse(03 Streamer Discharge in Air," Appl. Phys. Res., vol. 1, no. 2, pp. 2-10, 2009. 104 [7] P. Lukes, M. Clupek, V. Babicky, V. Janda, and P. Sunka, "Generation105 Ozone by Pulsed Corona Discharge over Water Surface in Hybrid Gas - Liquia6 Electrical Discharge Reactor," J. Phys. D. Appl. Phys., vol. 38, pp. 409-4167 2005.

[8] D. M. Stanbury, "Reduction potentials involving inorganic free radicalsli@9 aqueous solution", Adv. Inorg. Checm, Vol. 33, pp. 69-138, 1989 [9] M. Malik, A. Ghaffar, S. Malik, "Water purification by electridall 1 discharges", Plasma Sources Sci. Technol., vol.10, pp. 82-91, 2001 A. T. Sugiarto, S. Ito, T. Ohshima, M. Sato, and J. D. Skanly, "Oxidatike3 Decoloration of Dyes by Pulsed Discharge Plasma in Water," J. Electrost., vb14 58, pp. 135-145, 2003.

11] X. Domenech, W. F. Jardim, M. I. Litter, "Advanced oxidation procesdel 6 for contaminant removal", In: Contaminants removal by heterogeneous photocatalysis, M.A. Blesa, B. Sánchez (Ed). Editorial CIEMAT, Madrid, Spain, 2004.

[12] D. Dobrynin, G. Fridman, G. Friedman, and A. Fridman, "Physical and Biological Mechanisms of Direct Plasma Interaction with Living Tissue," New J. Phys., vol. 11, pp. 1-26, 2009.

[13] G. Fridman, A. D. Brooks, M. Balasubramanian, A. Fridman, A. Gutsol, V. N. Vasilets, H. Ayan, and G. Friedman, "Comparison of Direct and Indirect Effects of Non-Thermal Atmospheric Pressure Plasma on Bacteria," Plasma Process. Polym., vol. 4, no. 4, pp. 370-375, 2007.

[14] L. F. Gaunt, C. B. Beggs, and G. E. Georghiou, "Bactericidal Action of th?7 Reactive Species Produced by Gas-Discharge Nonthermal Plasma at Atmospheric Pressure : A Review," IEEE Trans. Plasma Sci, vol. 34, no. 4, pp. 1257-1269, 2006.

[15] J. Foster, G. Adamovsky, S. Gucker, I. Blankson, "A Comparative Study of the Time-Resolved Decomposition of Methylene Blue Dye Under the Action of a Nanosecond Repetitively Pulsed DBD Plasma Jet Using Liquid Chromatography and Spectrophotometry", IEEE Trans. Plasma Sci, vol. 41, no. 3, pp.503-512, 2013.

[16] J. Foster, B. Sommers, S. Gucker, I. Blankson, G. Adamovsky, "Perspectives on the Interaction of Plasmas With Liquid Water for Water", IEEE Trans. Plasma Sci, vol. 40, n. 5, 2012, pp.1311-1323

17] M. Malik, "Water Purification by Plasmas: Which Reactors are M\$339 Energy Efficient?”, Plasma Chem. Plasma Process, v.30, pp.21-31, 2010. 140 [18] S. J. Macgregor, J. M. Koutsoubis, and S. M. Turnbull, "The Design Ah41 Operation of A Compact High-Voltage, High Pulse Repetition Frequenk 42 Trigger Generator," Meas. Sci. Technol., vol. 9, no. 11, pp. 1899-1905, $199 \$ 43$
[19] Z. Machala, M. Morvova, E. Marode, I. Morva, "Removal of cyclohexanone in transition electric discharges at atmospheric pressure", $J$. Phys. D.: Appl. Phys., v.33, pp.3198-3213, 2000.

[20] M. Janda, V. Martisovits, Z. Machala, "Transient spark: a dc-driven repetitively pulsed discharge and its control by electric circuit parameters", Plasma Sources Sci. Technol., v.20, pp.035015 (10pp), 2011.

[21] Z. Machala, E. Marode, M. Morvova, P. Lukas, "DC glow discharge in atmospheric air as a source for organic compounds abatement", Plasma Process. Polym, v.2, pp.152-161, 2005.

[22] Z. Machala, I. Jedlovsky, L. Chladekova, B. Pongrac, D. Giertl, M. Janda, L. Sikurova, P. Polcic, "DC discharges in atmospheric air for biodecontamination -spectroscopic methods for mechanism identification", Eur. Phys J. D, v.54, n.2, pp. 195-204, 2009

[23] Y. Minamitani, S. Shoji, Y. Ohba, Y. Higashiyama, "Decomposition of Dye in Water Solution by Pulsed Power Discharge in a Water Droplet Spray", IEEE Trans. Plasma Sci, vol. 36, no. 5, pp.2586-2591, 2008.

[24] E. Sysolyatina, A. Mukhachev, M. Yurova, M. Grushin, V. Karalnik, A. Petryakov, N. Trushkin, S. Ermolaeva, Y. Akishev, "Role of the Charged Particles in Bacteria Inactivation by Plasma of a Positive and Negative Corona in Ambient Air", Plasma Process. Polym., v.11., n.4, pp.1612-8869, 2014 [25] E. Stoffels, Y. Sakiyama, and D. B. Graves, "Cold Atmospheric Plasma : Charged Species and Their Interactions With Cells and Tissues," IEEE Trans. Plasma Sci., vol. 36, no. 4, pp. 1441-1457, 2008.

[26] Y. Gorbanev, D. O'Connell, V. Chechik, "Non-Thermal Plasma in Contact with Water: The Origin of Species", Chem. Eur. J., v. 22, pp. 3496-3505, 2016 [27] J.L. Brisset, J. Lelievre, A. Doubla, J. Amouroux. "Interactions with aqueous solutions of the air corona products", Revue de Physique Appliquee, vol.25, n.6, pp.535-543, 1990

[28] R .Zhang, C. Zhang, X Cheng, L. Wang, Y. Wu, Z Guan, "Kinetics of decolorization of azo dye by bipolar pulsed barrier discharge in a three-phase discharge plasma reactor", J Hazard Mater., v.142, n.1-2, pp.105-110, 2007. [29] M. Selma and K. Takashima "Decolorization of indigo carmine dye by spark discharge in water", Int. J. of Plasma Env. Sci. and Tech., v.2, n.1, pp.5664, 2008

[30] J. Gao, X. Wang, Z. Hu, H. Deng, J. Huo, X. Lu, J. Kang, "Plasma degradation of dyes in water with contact glow discharge electrolysis", Water Research, v.37, pp.267-272, 2003

[31] Y. Z. Wen, H. J. Liu, W. P. Liu, X. Jiang, "Degradation of Organic Contaminants in Water by Pulsed Corona Discharge," Plasma Chem. Plasma Process., vol. 5, no. 2, pp. 137-146, 2005.

[32] A. T. Sugiarto, T. Ohshima, and M. Sato, "Advanced Oxidation Processes Using Pulsed Streamer Corona Discharge In Water," Thin Solid Films, vol. 407, no. 1-2, pp. 174-178, 2002.

[33] S. Muradia, "Study of low-voltage pulsed plasma discharges inside water using a bubble-generating porous ceramic electrode for wastewater treatment", PhD Thesis, Shizuoka University, Japan, 2013

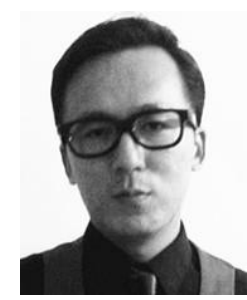

Sirui Li was born in Yunnan, China, in 1988. He received the B.Eng. (with honors), M.Sc. degrees in Electronic and Electrical Engineering from the University of Strathclyde, Glasgow, U.K., in 2010 and 2011. He is currently a Ph.D. student at the University of Strathclyde, majoring in non-thermal plasma discharge for air treatment and surface decontamination.

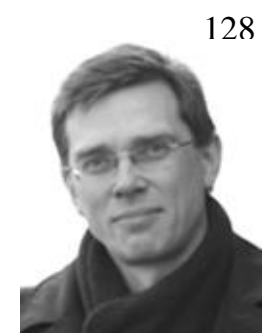

28 Igor V. Timoshkin (M'07, SM'14) received the degree in physics from the Moscow State University (Russia) in 1992, and the Diploma and the Ph.D. degree from the Imperial College of Science, Technology and Medicine, (London, UK) in 2001. After graduation from MSU he worked as a Researcher at Moscow State Agro-Engineering University, and then at the Institute for High Temperatures of Russian Academy of Sciences before moving to ICSTM in 1997. He joined the Department of Electronic and Electrical Engineering of the University of Strathclyde (Glasgow, UK) in 2001 where he became a Reader in 2016. His research interests include properties of solid and liquid dielectric materials, electronics of plasma discharges in condensed media, practical applications of electrohydraulic and high-power ultrasound pulses, bio-dielectrics and effects of electromagnetic fields on biological objects. 


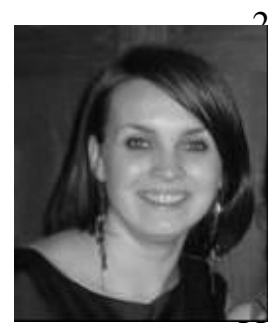

Michelle Maclean was born on the Isle of Lewis, Scotland, in 1980. She received the B.Sc. $\left(1^{\text {st }}\right.$ class honors) degree in Microbiology and Immunology in 2002, and the Ph.D. degree in Electronic and Electrical Engineering in 2006, both from the University of Strathclyde, Glasgow, U.K. She is presently working as a Research Fellow at the Robertson Trust Laboratory for Electronic Sterilization Technologies (ROLEST) at the University of Strathclyde, and her interdisciplinar\$5
12

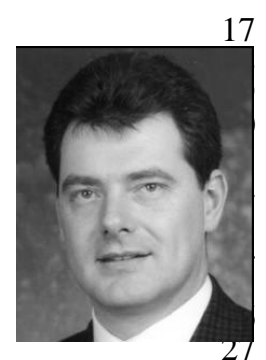

Scott J. MacGregor (M'95) received the B.Sc. and $\mathrm{Ph} . \mathrm{D}$. degrees from the University of Strathclyde, Glasgow, U.K., in 1982 and 1986, respectively. He is currently with the University of Strathclyde, where he became a Pulsed-Power Research Fellow in 1986, a Lecturer in pulsed-power technology in 1989, a Senior Lecturer in 1994, and a Reader and a Professor of highvoltage engineering in 1999 and 2001, respectively. He has been Dean of Engineering at the University of Strathclyde since January 2010. His research interests

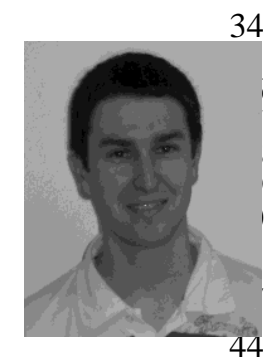

Mark P. Wilson (M'10) was born in Stranraer, Scotland, in 1982. He received the B.Eng. (with honours), M.Phil., and Ph.D. degrees in electronic and electrical engineering from the University of Strathclyde, Glasgow, U.K., in 2004, 2007, and 2011, respectively. He is presently working as a Teaching Associate at the University of Strathclyde, where he continues to investigate surface flashover of solids immersed in insulating oil. Mark is a member of the 44 IEEE Nuclear and Plasma Sciences Society, from

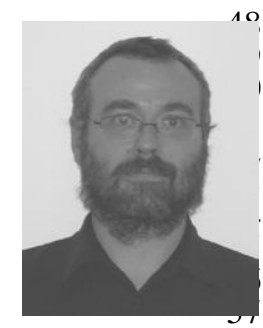

Martin J. Given (M'99-SM'11) is currently a Senior Lecturer in the Department of Electronic and Electrical Engineering at the University of Strathclyde. He received a degree in physics from the University of Sussex in 1981 and a PhD in electronic and electrical engineering from the University of Strathclyde in 1996. His research interests include, ageing processes and condition monitoring in solid and liquid insulation systems, high speed switching and pulse power applications.

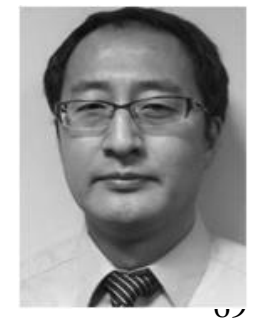

Tao Wang received the B.Eng and M.Sc degrees from Northeast China Dianli University (China) in 1993 and 1996 respectively, and the Ph.D. degree from the University of Strathclyde (Glasgow, UK) in 2005. He then joined the Newland Entech as a research fellow developing high efficiency industrial ozone generator. He joined the department of Electronic and Electrical Engineering of University of Strathclyde as a lecturer in 2010. His research interests include non-thermal gas discharges and their applications in gas synthesis, water disinfection and advanced oxidation process in water.

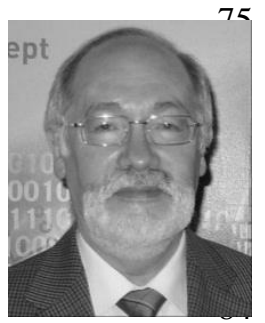

John Anderson was born in Glasgow, U.K., on September 2, 1942. He received the B.Sc. degree in applied microbiology in 1968, and the Ph.D. degree in fungal physiology in 1971, both from the University of Strathclyde, Glasgow. Since 1971, he has been with the Department of Bioscience and Biotechnology, University of Strathclyde, where he became a Professor of Microbiology and Head of Department. $\mathrm{He}$ is currently an Emeritus Professor at the University of Strathclyde. His research interests include various aspects of food, biomedical and environmental microbiology with interdisciplinary collaboration on the application of electro-technologies for electronic pasteurization and sterilization 